\title{
Obituary
}

\section{Bernard N. Fields 1938-1995}

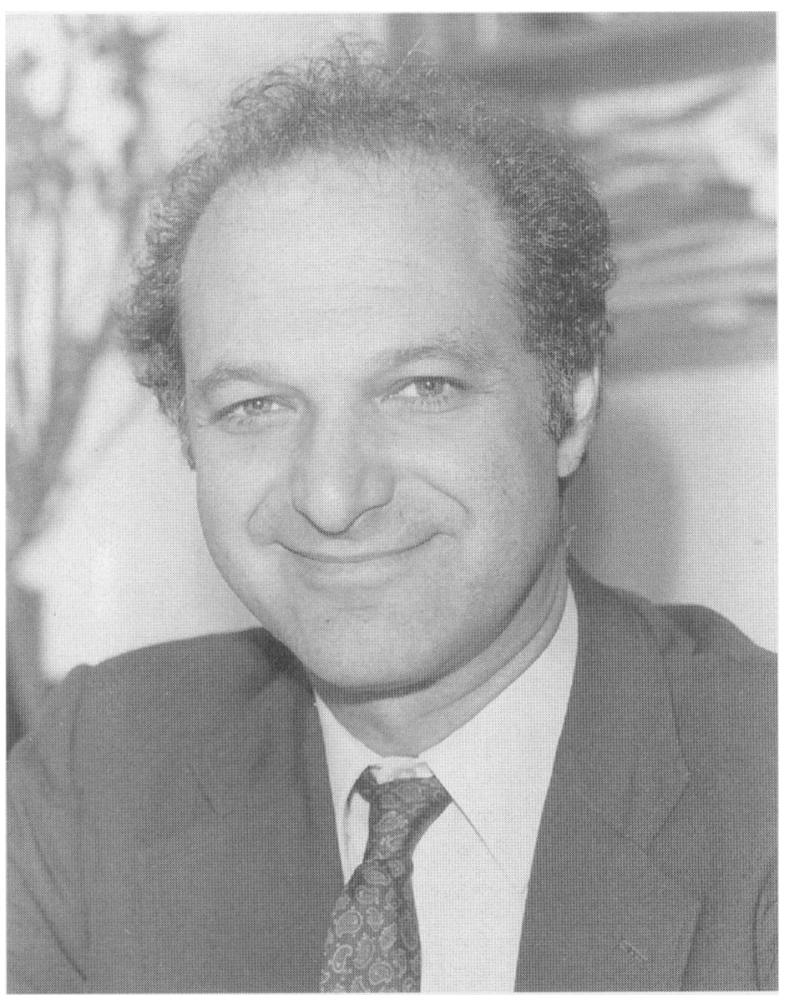

Dr. Bernard Fields died of pancreatic cancer on February 7.

Born in Brooklyn, he obtained an A.B. from Brandeis University and an M.D. from New York University School of Medicine. After clinical training in Medicine and Infectious Diseases at the Beth Israel and Mass General Hospitals in Boston, he moved to the National Communicable Disease Center in Atlanta as a medical virologist. Two years later he joined the faculty of Albert Einstein College of Medicine in New York where he initiated his studies on reovirus with Dr. W.K. Joklik. In 1975, he returned to Boston where he became chairman of the department of
Microbiology and Molecular Genetics and Adele H. Lehman Professor of Microbiology and Molecular Genetics at Harvard Medical School.

Throughout his research career, he developed a simple viral system, reovirus infection of mice, to study viral pathogenesis. Because different serotypes of reovirus cause different pathologic manifestations, Dr. Fields and his colleagues used reassortant viruses to map the viral genes associated with different disease syndromes or with distinct steps in viral pathogenesis. The elegance of this experimental paradigm and the clarity of the experimental results obtained generated considerable and renewed interest in viral pathogenesis studies. His now classical studies on the interaction between a virus and its host established an intellectual foundation on which much of today's virological research, including that on AIDS, is based.

For his enumerable contributions, Dr. Fields was regarded by many as an intellectual leader in the field of virology. He served as adviser to numerous organizations and was recently considered for the position of AIDS "czar" but had to withdraw from consideration because of his disease. He was the editor-in-chief of the standard textbook of virology (Fields Virology, Raven Press, 1990).

His contributions to virology and medicine were recognized by many honors including membership in the National Academy of Sciences and its Institute of Medicine.

During an all too brief period of remission, he continued to participate in new and forwardlooking projects. Thus, in the last year, he became one of the most valued contributing editors to Molecular Medicine and a member of the Council of the newly formed Molecular Medicine Society. His willingness to participate and his quiet wisdom will be sorely missed. 